\title{
Genetic architecture of main effect QTL for heading date in European winter wheat
}

\author{
Christine Zanke1, Jie Ling ${ }^{1}$, Jörg Plieske ${ }^{2}$, Sonja Kollers ${ }^{3}$, Erhard Ebmeyer ${ }^{3}$, Viktor Korzun ${ }^{3}$, \\ Odile Argillier ${ }^{4}$, Gunther Stiewe ${ }^{5}$, Maike Hinze ${ }^{5}$, Sebastian Beier ${ }^{1}$, Martin W. Ganal ${ }^{2}$ and \\ Marion S. Röder ${ }^{1 *}$ \\ ${ }^{1}$ Department of Cytogenetics and Genome Analyses, Leibniz Institute of Plant Genetics and Crop Plant Research (IPK), Gatersleben, Germany \\ 2 TraitGenetics GmbH, Gatersleben, Germany \\ ${ }^{3}$ KWS LOCHOW GmbH, Bergen, Germany \\ ${ }^{4}$ Syngenta Seeds S.A.S., Orgerus, France \\ ${ }^{5}$ Syngenta Seeds GmbH, Bad Salzuflen, Germany
}

Edited by:

Klaus Pillen, Martin-Luther-

University Halle-Wittenberg,

Germany

Reviewed by:

Dongying Gao, University of

Gerogia, USA

Tobias Würschum, State Plant

Breeding Institute, Germany

*Correspondence:

Marion S. Röder, Department of Cytogenetics and Genome

Analyses, Leibniz Institute of Plant Genetics and Crop Plant Research (IPK), Corrensstr. 3, Gatersleben 06466, Germany

e-mail: roder@ipk-gatersleben.de
A genome-wide association study (GWAS) for heading date (HD) was performed with a panel of 358 European winter wheat (Triticum aestivum L.) varieties and 14 spring wheat varieties through the phenotypic evaluation of $H D$ in field tests in eight environments. Genotyping data consisted of 770 mapped microsatellite loci and 7934 mapped SNP markers derived from the $90 \mathrm{~K}$ iSelect wheat chip. Best linear unbiased estimations (BLUEs) were calculated across all trials and ranged from 142.5 to 159.6 days after the 1 st of January with an average value of 151.4 days. Considering only associations with a $-\log _{10}(P$-value $) \geq 3.0$, a total of 340 SSR and 2983 SNP marker-trait associations (MTAs) were detected. After Bonferroni correction for multiple testing, a total of 72 SSR and 438 SNP marker-trait associations remained significant. Highly significant MTAs were detected for the photoperiodism gene Ppd-D1, which was genotyped in all varieties. Consistent associations were found on all chromosomes with the highest number of MTAs on chromosome 5B. Linear regression showed a clear dependence of the HD score BLUEs on the number of favorable alleles (decreasing HD) and unfavorable alleles (increasing HD) per variety meaning that genotypes with a higher number of favorable or a low number of unfavorable alleles showed lower HD and therefore flowered earlier. For the vernalization gene $\mathrm{Vrn}-\mathrm{A2}$ co-locating MTAs on chromosome $5 \mathrm{~A}$, as well as for the photoperiodism genes Ppd-A1 and Ppd-B1 on chromosomes 2A and 2B were detected. After the construction of an integrated map of the SSR and SNP markers and by exploiting the synteny to sequenced species, such as rice and Brachypodium distachyon, we were able to demonstrate that a marker locus on wheat chromosome $5 \mathrm{BL}$ with homology to the rice photoperiodism gene $\mathrm{Hd} 6$ played a significant role in the determination of the heading date in wheat.

Keywords: genome wide associations, Triticum aestivum L., photoperiodism, environmental adaptation, flowering time

\section{INTRODUCTION}

Heading date (HD) is one of the critical traits for the adaptation of bread wheat (Triticum aestivum L.) to diverse climatic environments and the cultivation in various regions and cropping seasons. The adaptability of wheat to a wide range of environments has been favored by allelic diversity in genes regulating growth habit and photoperiod response. Differences in the vernalization genes $(V r n)$ determine spring and winter wheat habits. The photoperiod genes $(P p d)$ play a major role in determining the flowering time and the sensitivity to photoperiodism. Earliness per se (Eps) genes influence flowering time independently from photoperiodism.

On a molecular level, regulation networks for heading and flowering are conserved between model species, such as Arabidopsis (Andrés and Coupland, 2012), as well as in dicotyledonous and monocotyledonous crop plants (Jung and Müller,
2009) including the temperate cereals (Cockram et al., 2007; Trevaskis et al., 2007; Distelfeld et al., 2009).

Positional cloning identified $P p d-H 1$, the major determinant of barley photoperiod response, as a pseudo-response regulator, which is an ortholog of the Arabidopsis photoperiod pathway gene CONSTANS (Turner et al., 2005). In wheat, an orthologous gene was identified as the $P p d-D 1$ gene on chromosome 2D (Beales et al., 2007). A semi-dominant mutation, Ppd-Dla widely used in the "green revolution," converts wheat from a long day (LD) to a photoperiod insensitive (day neutral) plant, providing adaptation to a broad range of environments. Recently it was shown that the bolting locus B of sugar beet, distinguishing annuals from biennials, is also a pseudo-response regulator gene named BOLTING TIME CONTROL 1 (BvBTC1) with similarity to the CONSTANS gene of Arabidopsis and $P p d-H 1$ in barley (Pin et al., 2012). Another photoperiodism gene, $P p d-B 2$, which was 
detected when plants were exposed to a long photoperiod, was mapped on chromosome 7BS in wheat (Khlestkina et al., 2009).

Similarily, the molecular mechanisms for the requirement of vernalization have been identified (Trevaskis et al., 2007; Distelfeld et al., 2009) in wheat. Natural variation in vernalization requirement in the temperate cereals is mainly associated with allelic differences in the VRN1, VRN2, and VRN3 vernalization genes. VRN1 encodes a MADS-box transcription factor with high similarity to Arabidopsis meristem identity genes APETALA1, CAULIFLOWER and FRUITFUL (Yan et al., 2003; Distelfeld et al., 2009). VRN2, a dominant repressor of flowering, is downregulated by vernalization. The $V R N 2$ region includes two similar ZCCT genes encoding proteins with a putative zinc finger and a CCT domain that have no clear homologs in Arabidopsis (Yan et al., 2004; Distelfeld et al., 2009). The vernalization gene VRN3 encodes a RAF kinase inhibitor like protein with high homology to Arabidopsis protein FLOWERING LOCUS T (FT) (Yan et al., 2006; Distelfeld et al., 2009).

The presence of earliness per se genes (Eps) has been demonstrated by QTL-mapping studies in barley and wheat since a long time (Laurie et al., 1995; Worland, 1996). Only recently the molecular identification of two EARLY MATURITY genes, eam 8 and eam10, has been reported in barley (Faure et al., 2012; Zakhrabekova et al., 2012; Campoli et al., 2013). Earliness per se genes have been fine-mapped in diploid or hexaploid wheat on chromosomes 1A and 3A (Faricelli et al., 2010; Gawronski and Schnurbusch, 2012).

Several QTL and meta-QTL mapping studies showed that in wheat, besides the known major loci, a wealth of additional chromosomal regions affect the flowering time (Sourdille et al., 2000; Hanocq et al., 2004, 2007; Griffiths et al., 2009; Rousset et al., 2011). Co-location of QTLs for agronomic traits, such as post-anthesis leaf senescence, grain yield or grain protein concentration with QTL for flowering time indicated pleiotropic effects of anthesis date (Bogard et al., 2011). Also in barley a number of flowering time QTL were associated with agronomic traits (Wang et al., 2010).

While with bi-parental mapping studies only a limited number of parental lines can be investigated, genome wide association studies (GWAS) are suitable for the monitoring of a larger germplasm panel (Zhu et al., 2008). The method is based on the meiotic events which occurred during the entire development of the lines and which results in an increased genetic resolution determined by the extent of linkage disequilibrium (LD) of the species under investigation (Hamblin et al., 2011). Whole-genome association mapping was applied in wheat for ear emergence (Le Gouis et al., 2012), as well as for yield and agronomic traits (Neumann et al., 2011; Reif et al., 2011; Wang et al., 2012) and resistance to pathogens (Crossa et al., 2007; Maccaferri et al., 2010; Miedaner et al., 2011; Yu et al., 2011, 2013; Letta et al., 2013; Kollers et al., 2013a,b).

The goal of our study was to map marker-trait associations (MTAs) for HD in a panel of European winter wheat varieties and to identify markers suitable for marker assisted selection. We were interested to compare the MTAs detected with genome wide SSR (simple sequence repeat) markers to the pattern of MTAs detected by a SNP (single nucleotide polymorphism) array.
Finally, we exploited the synteny of the SNP marker sequences to other grass species with complete genome sequence, such as rice and Brachypodium distachyon, in order to detect relationships to already described genes connected to the regulation of photoperiodism and flowering time.

\section{MATERIALS AND METHODS PLANT MATERIAL AND PHENOTYPING}

The plant material, consisting of 358 European winter wheat varieties plus 14 spring wheat varieties as an outgroup, is described in more detail in Kollers et al. (2013a). Field trials were conducted in the season 2008/2009 in Andelu/France (09.AND), Seligenstadt/ Germany (09.SEL) and Wohlde/Germany (09.WOH) and in the season 2009/2010 in Andelu/France (10.AND), Janville/France (10.JAN), Saultain/France (10.SAU), Seligenstadt/Germany (10. SEL) and Wohlde/Germany (10.WOH) by applying an alpha design with two replications per site. Both winter and spring varieties were sown in autumn and HD was recorded as the developmental stage at that time, by counting days from the 1st of January, when ears of approximately half of the genotypes were fully visible (Supplemental Table 1).

\section{MOLECULAR DATA ANALYSIS, GENETIC MAPPING AND ANALYSIS OF SYNTENY}

For marker-trait analysis a set of 732 microsatellite markers, resulting in 770 different loci spread across all chromosomes of wheat was used. Of these 770 loci, 635 loci were mapped and 135 loci were unmapped. Since the microsatellites are multiallelic, they amounted to 3176 alleles. More details about this data set and the description of LD and population structure are provided in Kollers et al. (2013a). For SNP-analysis a novel 90k Infinium chip (90k iSELECT) was genotyped on all 372 varieties (Cavanagh et al., 2013; Wang et al., 2014). This resulted in a total of 21742 scorable and polymorphic markers on our association panel by considering all polymorphic markers with a minor allele frequency $(\mathrm{MAF})>0.03$. Of these markers, only the 7934 mapped markers were included in the association analysis, while the unmapped markers were not used for association analysis. The SSR-markers were mapped on the ITMI-population (International Triticeae Initiative) based on recombinant inbred lines between the parents W7984 (synthetic wheat) $\times$ Opata M85 (Röder et al., 1998; Ganal and Röder, 2007), while the SNP markers were mapped on 138 lines of a newly created doubled-haploid population of the same parents (Sorrells et al., 2011; Poland et al., 2012). Map construction was performed using the software package Joinmap 4.1. Both maps have different recombination values, and currently only few common markers are available, which makes comparisons difficult. For display a reduced version of the SNP-map was used containing all relevant markers with MTAs for HD.

In order to establish the synteny of interesting MTA loci to rice, a BLAST X (cutoff: $e$-value of 10E-2) was conducted against the data base of MSU Rice Genome Annotation Project Release 7.0 (http://rice.plantbiology.msu.edu/) for all SNP markers with significant $\left(-\log _{10}(P\right.$-value $\left.) \geq 3.0\right)$ MTAs for HD. For the blast search the flanking sequences of the SNP markers (101-201 bp in length) according to Wang et al. (2014) were used. The resulting 
3877 syntenic relationships were filtered for chromosomal synteny as described by Salse et al. (2009) resulting in 956 syntenic relationships. For comparison to literature data in some cases the ID converter (http://rapdb.dna.affrc.go.jp/tools/converter/run? type $=$ rap- $\mathrm{msu} ; \mathrm{id}=\mathrm{Os} 1 \mathrm{~g} 0157100)$ was used in order to compare to locus designations of the RAP-DB rice annotation project database (http://rapdb.dna.affrc.go.jp/).

For detecting the synteny to Brachypodium distachyon a BLAST X (cutoff: $e$-value of 10E-2) was conducted against version 1.2 of the MIPS annotation (http://mips.helmholtz-muenchen.de/ plant/brachypodium/download/index.jsp) resulting in 3404 syntenic relationships. Those were filtered according to the expected chromosomal synteny (The International Brachypodium Initiative, 2010) resulting in 1575 syntenic relationships.

As candidate genes the photoperiodism gene $P p d-D 1$ (Beales et al., 2007) and the vernalization genes Vrn-B1 and Vrn-D1 (Zhang et al., 2008) were genotyped on all varieties.

\section{STATISTICAL ANALYSIS AND ASSOCIATION MAPPING}

Each year-location combination was considered as an environment in our study. For each environment and genotype the adjusted mean of two replications was calculated as the phenotypic data using GenStat 13th edition as

$$
\mathrm{y}=\mu+\text { replication }+ \text { genotype }+ \text { block }+\mathrm{e}
$$

with replication and genotype as fixed factors and block as random factor and block nested within replication; $\mu$ represents an overall mean and e is a residual term.

In addition, best linear unbiased estimations (BLUEs) across all eight environments were calculated using the software package GenStat 14th edition (VSN International, Hemel Hempstead, Hertfordshire, UK) as described in Kollers et al. (2013a) with

$$
\mathrm{y}=\mu+\text { genotype }+ \text { environment }+\mathrm{e}
$$

with genotype and environment as fixed effects; $\mu$ represents an overall mean and e is a residual term. Since the datasets for all environments were complete and balanced, the BLUEs, in fact, equaled the arithmetic means across environments.

For calculating genotype-phenotype associations a minor allele frequency (MAF) threshold of 3\% (equaling 11 varieties) was applied to all markers. A mixed model for association mapping was calculated using the software package GenStat 14th edition as described in Kollers et al. (2013a) by applying a kinship matrix as relationship model.

$$
\begin{aligned}
& \mathrm{P}_{\mathrm{i}}=\mu+\mathrm{x}_{\mathrm{i}} \alpha+\mathrm{G}_{\mathrm{i}}+\mathrm{e} \\
& \text { with } \mathrm{G}_{\mathrm{i}} \sim \mathrm{N}\left(0,2 \mathrm{~K} \sigma_{\mathrm{g}}^{2}\right), \text { error } \sim \mathrm{N}\left(0, \sigma^{2}\right)
\end{aligned}
$$

$\mathrm{x}_{\mathrm{i}}$ is the marker score for cultivar $\mathrm{i}, \alpha$ is the marker fixed effect, $\mu$ represents an overall mean, $\mathrm{e}$ is a residual term and $\mathrm{G}_{\mathrm{i}}$ represents the score of genotype corrected by kinship matrix $(\mathrm{K})$ to structure random genotypic effects.

The Loiselle kinship matrix was calculated for 155 SSR markers, equally distributed on the genome, by using the software package SPAGeDi (Hardy and Vekemans, 2002). This kinship matrix was applied to correct for false positives for calculating MTAs with SSR as well as with SNP markers as described by Matthies et al. (2012). The threshold of Bonferroni correction for multiple testing was calculated by dividing $P<0.01$ with the number of SSR or SNP markers used for the analysis.

Additive effects and marker effects $\left(r^{2}\right)$ were estimated using the software package TASSEL 3.0.

Spearman rank order correlations and ANOVA using the adjusted means of the eight environments were calculated with the software package SigmaPlot 11.0. The heritability was calculated from the variance components according to the formula: $H^{2}=\operatorname{Var}($ genotype)/(Var (genotype) $+\operatorname{Var}($ error)/no. of locations) with variance components calculated with the software package SPSS v. 19. This software was also used to conduct a trait Post-hoc test according to Tukey B.

\section{RESULTS \\ DESCRIPTION OF PHENOTYPIC DATA}

The phenotypic data for 358 European winter wheat varieties plus 14 spring wheat varieties were based on field evaluations in eight environments. The resulting best linear unbiased estimations for heading time across all environments ranged from 142.5 to 159.6 days after 1st of January with an average of 151.4 days (Supplemental file 1). All 14 spring varieties, which had been sown at the same time as the winter varieties were found in the early segment of HD (Figure 1A). Also all 53 varieties carrying the photoperiodism insensitive mutant of gene $P p d-D 1$ on chromosome 2DS (Beales et al., 2007) were in the first half of the phenotypic distribution, with the exception of winter wheat variety "Paledor," which was found in the second half of the phenotypic distribution (Figure 1B). The Spearman Rank Order correlation coefficients of the HD scores among the environments and with the BLUEs ranged from 0.843 to $0.973(P<0.001)$, indicating

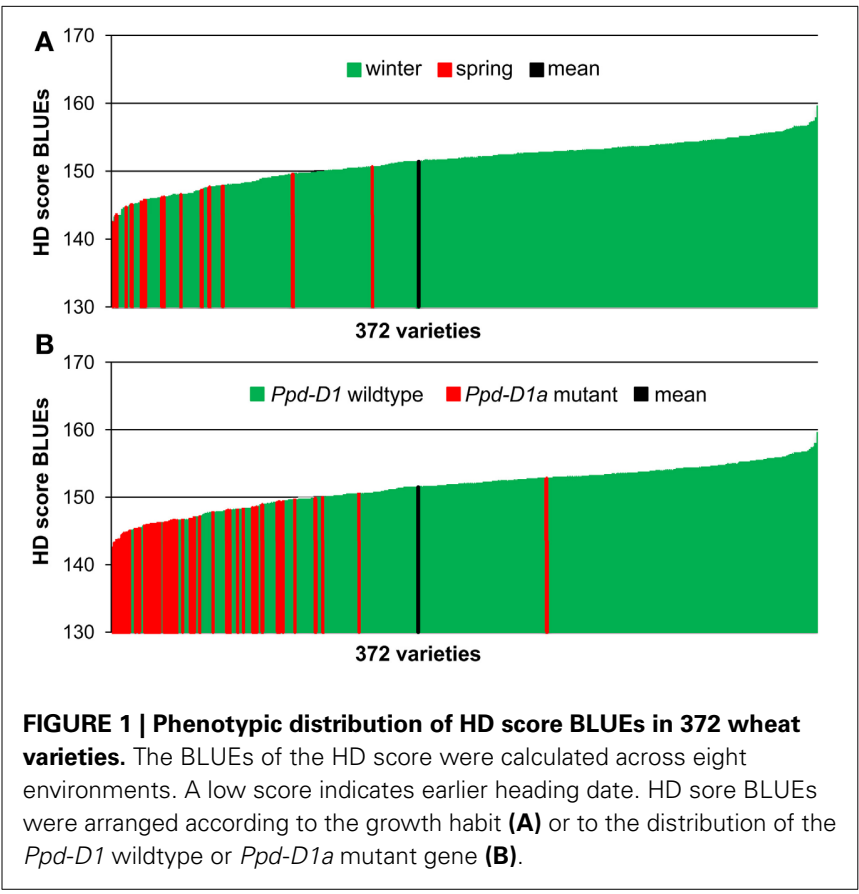


a high reproducibility of the ranking of varieties grown in different locations (Supplemental file 2). The analysis of variance (ANOVA) was significant for genotype as well as environment (Supplemental file 3). A Tukey B-test detected six different class means for the environments ranging from 144.5 to 161.5 days, which is also reflected in a broad sense heritability of $H^{2}=0.609$ (Supplemental file 4).

\section{DETECTION OF MARKER-TRAIT ASSOCIATIONS (MTAs)}

MTAs were calculated separately for each environment plus the resulting BLUEs by employing a mixed linear model with a kinship matrix. Two sets of genotypic data were used: First, a set of 732 microsatellite markers (SSRs) resulting in 770 loci spread across the 21 chromosomes of wheat, and secondly, a set of 7934 SNP markers coming from the 90K wheat iSELECT array. While the SNP markers represent a bi-allelic marker system, the microsatellites provide multiple alleles per locus resulting in a total number of 3176 alleles. The microsatellite data were described in former whole genome association studies (Kollers et al., 2013a,b) and provide good genomic coverage of all chromosomes. The SNP data were mapped to all chromosomes, but due to the lack of polymorphism, the chromosomes of the D-genome were less covered than those of the genomes A and B (Supplemental file 5).

A total of 340 SSR and 2983 SNP MTAs reached a standard threshold of $\log _{10}(P$-value $) \geq 3.0$ (corresponding to a $P$-value $<$ 0.001 ). These included 42 BLUEs for the SSRs and 326 BLUEs for the SNPs. After applying a Bonferroni correction for multiple testing (with $\alpha=0.01$ ), a $-\log _{10}(P$-value $) \geq 4.82$ for SSR and $a-\log _{10}(P$-value $) \geq 5.89$ for SNP were considered as significant. After this correction, a total of 72 SSR and 438 SNP MTAs remained significant (Table 1, Figure 2, Supplemental files 5-7), which included 10 BLUEs for the SSRs and 51 BLUEs for the SNPs. A total of 79 different marker loci were involved in MTAs detection for the SSR markers and 758 marker loci for SNP markers corresponding to a $-\log _{10}(P$-value $) \geq 3.0$ (Supplemental file

Table 1 | Number of MTAs per environment for the SSR marker and the SNPs on the 90K iSelect chip.

\begin{tabular}{|c|c|c|c|c|}
\hline \multirow[t]{2}{*}{ Environments } & \multicolumn{2}{|c|}{ SSR } & \multicolumn{2}{|c|}{ 90K iSelect } \\
\hline & $\begin{array}{c}-\log _{10} \\
(P \text {-value }) \\
\geq 3.0\end{array}$ & $\begin{array}{c}-\log _{10} \\
(P \text {-value }) \\
\geq 4.82\end{array}$ & $\begin{array}{c}-\log _{10} \\
(P \text {-value }) \\
\geq 3.0\end{array}$ & $\begin{array}{c}-\log _{10} \\
(P \text {-value }) \\
\geq 5.89\end{array}$ \\
\hline Andelu (2009) & 45 & 9 & 325 & 60 \\
\hline Seligenstadt (2009) & 29 & 5 & 254 & 43 \\
\hline Wohlde (2009) & 30 & 9 & 337 & 39 \\
\hline Andelu (2010) & 34 & 4 & 253 & 27 \\
\hline Janvielle (2010) & 23 & 3 & 232 & 33 \\
\hline Saultain (2010) & 44 & 8 & 290 & 47 \\
\hline Seligenstadt (2010) & 52 & 13 & 583 & 94 \\
\hline Wohlde (2010) & 41 & 11 & 383 & 44 \\
\hline BLUES & 42 & 10 & 326 & 51 \\
\hline Sum & 340 & 72 & 2983 & 438 \\
\hline
\end{tabular}

5). Since many marker loci co-segregated or were closely linked in the genetic map, marker loci with distances $\leq 1.0 \mathrm{cM}$ were combined. When considering only the BLUEs with $\log _{10}(P$-value $) \geq$ 3.0 , the number of combined marker loci was 30 for the SSRs and 92 for the SNPs (Supplemental file 5).

Many marker loci were significant for several environments (Figure 3, Supplemental file 8) with up to nine significant MTAs per marker locus (eight environments plus BLUEs). The number of significant MTAs varied considerably among the various chromosomes. For both marker types the highest number of significant MTAs was detected on chromosome 5B before Bonferroni correction, while after Bonferroni correction most SSR loci were significant on chromosome 6D (Supplemental file 5).

The comparison of the SSR map with the SNP map is still difficult, because the two maps were constructed on different mapping populations and contain only few common markers. Based on the mapping positions, some MTAs can be matched between SSR and SNP markers. An example is the MTA with SSR marker GWM1130 at the distal end of chromosome 1BS and the SNP marker Kukri_c38553_173. Overall, many additional marker loci were significant for the SNPs as compared to the SSR markers.

Highly significant MTAs were detected for the photoperiod sensitivity gene $P p d-D 1$ on chromosome arm 2DS. In all environments and the BLUEs the photoperiod insensitive mutant allele $P p d-D 1 a$ led to a decreased HD score, which means earlier heading (Figure 4, Supplemental file 9). The mutant allele of $P p d-D 1 a$ was detected in a total of 53 varieties including five spring varieties (Supplemental file 1). Additionally, the candidate gene markers for Vrn-B1 and Vrn-D1 were genotyped. While VrnD1 was monomorphic for all winter varieties and a second allele detected in only two spring varieties (Supplemental file 1), Vrn$B 1$ had a dominant allele for three spring varieties, but also three winter varieties (Buteo, Discus and Lona). Since both markers were below the threshold of minor allele frequency, they were not included in the regular analysis for MTAs. When they were tested for associations without setting a MAF, no significant association results were detected for $V r n-B 1$ and significant MTAs in two environments were detected for Vrn-D1 (Supplemental file 10).

\section{ADDITIVE EFFECTS FOR FAVORABLE AND UNFAVORABLE ALLELES}

In the following section, marker alleles with a negative additive effect leading to earlier heading will be referred to as "favorable alleles" and vice versa marker alleles leading to later heading as "unfavorable alleles." We are aware, that earlier heading is not favorable in all circumstances; the designation is mainly meant to facilitate the following description of the allele effects.

Considering the SSR markers, the varieties contained between zero to 25 favorable alleles and between six to 28 unfavorable alleles (Figure 5). A significant Spearman Rank Order correlation of $R=-0.697(P=0.00000020)$ existed between the HD BLUEs score and number of favorable alleles; for the HD BLUEs score and the number of unfavorable alleles the Spearman Rank correlation coefficient was $R=0.642(P=0.00000020)$. Linear regression showed a dependence of the HD BLUEs score from the number of favorable alleles with $R^{2}=0.577$ and $Y=155.0-$ $0.4 \mathrm{X}$; for the unfavorable alleles $R^{2}=0.503$ and $Y=141.6+$ $0.5 \mathrm{X}$ was observed (Figure 6). This means that varieties with a 

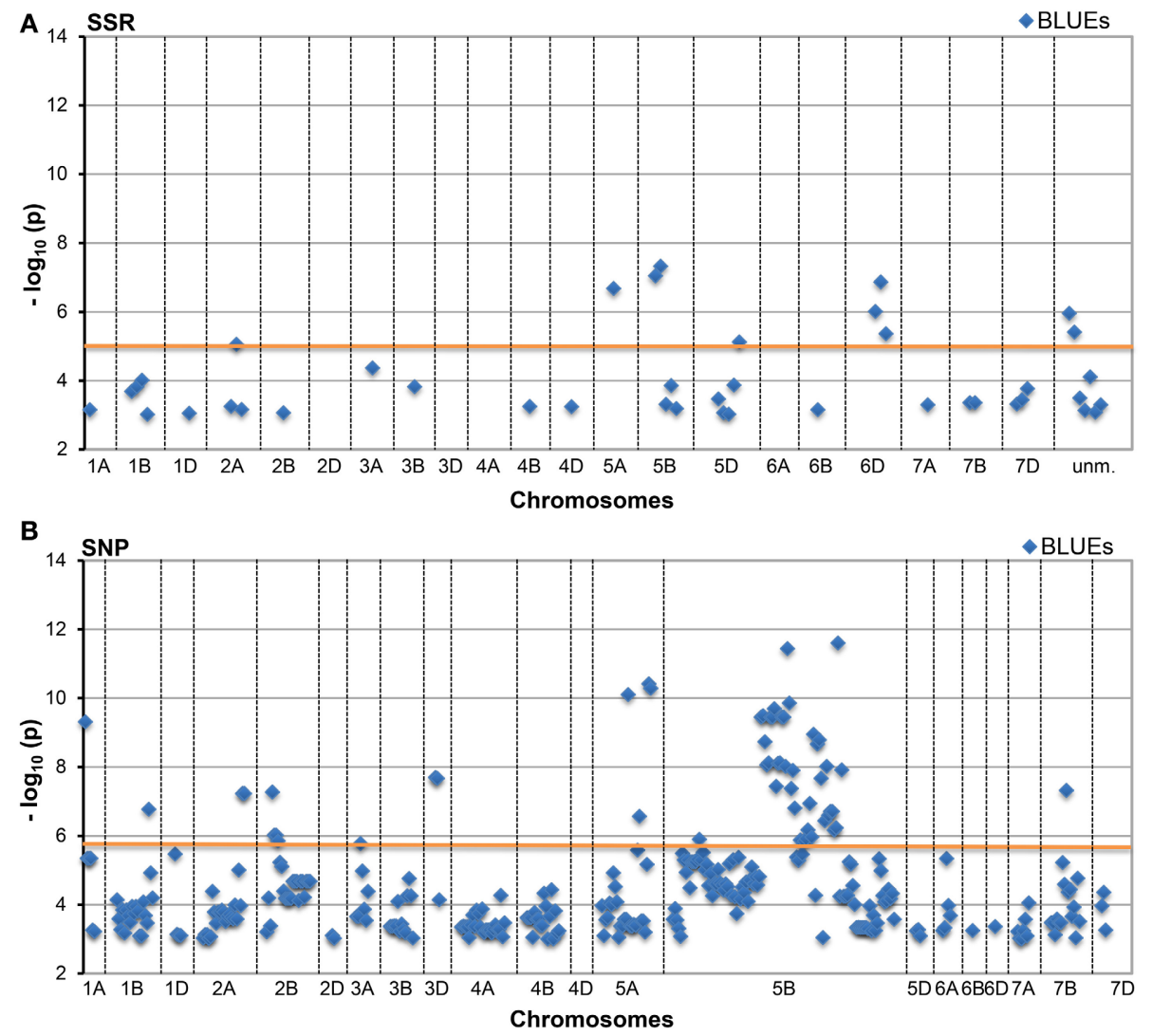

FIGURE 2 | Manhattan Plots of (A) SSR and (B) SNP marker alleles associated with HD BLUEs. This plot presents significant alleles associations at threshold $-\log _{10}(P$-value $) \geq 3.0$ for BLUEs sorted according to their chromosomal location. The red line indicates the threshold $-\log _{10}$ $(P$-value $) \geq 4.82$ (SSR) and $\geq 5.89$ (SNP), respectively, for Bonferroni correction. higher number of favorable alleles and a lower number of unfavorable alleles have an earlier heading time. The regression of favorable minus unfavorable alleles against the HD BLUEs score was $Y=148.5-0.3 \mathrm{X}$ with $R^{2}=0.603$ (Supplemental file 11).

We calculated the same regressions by taking the best or worst 20, 10 or 5 marker alleles into account (Figure 6, Table 2). These included the SSR markers with significant associations with a $-\log _{10}(P$-value $) \geq 3.0$ and the candidate gene $P p d-D 1$. The selection was based on the mean additive effect as described in Supplemental file 5. Even with only five marker alleles, significant regressions with $R^{2}=0.372$ for the favorable alleles and $R^{2}=0.326$ for the unfavorable alleles were observed. Therefore the chosen marker alleles are good candidates for adapting the HD in breeding programs by marker assisted selection.

\section{EXPLOITATION OF SYNTENY TO RICE AND BRACHYPODIUM DISTACHYON}

After conducting a BlastX to the rice genomic sequence and filtering for the synteny relationships between wheat and rice described by Salse et al. (2009) a total of 956 syntenic relationships between significant wheat SNP markers and the rice genome were established (Supplemental file 12). For Brachypodium distachyon, a total of 1575 syntenic relationships to the wheat markers were found after filtering for synteny according to the described chromosomal relationships (The International Brachypodium Initiative, 2010) (Supplemental file 13).

In the publication of Higgins et al. (2010) all known genes related to flowering time pathways were blasted to Brachypodium and rice. A comparison of our list of syntenic rice loci (Supplemental file 12) to their detected homologs gave two direct hits for the wheat marker Kukri_c10016_369 to two rice loci at LOC_Os03g10940.1 and LOC_Os03g55490.1. Both genes are coding for expressed putative protein casein kinase II subunit alpha-2, which both have homology to the rice gene Hd6 located at LOC_Os03g55389 (Takahashi et al., 2001). Also for Brachypodium homologs four direct hits with the same wheat marker Kukri_c10016_369 were found (Bradilg07750.1, Bradilg07810.1, Bradilg59010.1, Bradilg70690.1), with all four genes belonging to the Hd6 gene family. Hd6 was cloned as a rice quantitative trait locus involved in photoperiod sensitivity and is thought to be involved in the plant phototransduction pathway. Wheat marker Kukri_c10016_369 was highly significant, even after Bonferroni correction, in all eight environments plus BLUEs and is part of a cluster of significant markers on chromosome 5B. In an analysis of LD it was shown, that LD existed between Kukri_c10016_369 and the highly significant SSR markers WMC160 and BARC232, especially the alleles discovering MTAs, WMC160_137bp, WMC160_190 bp, 


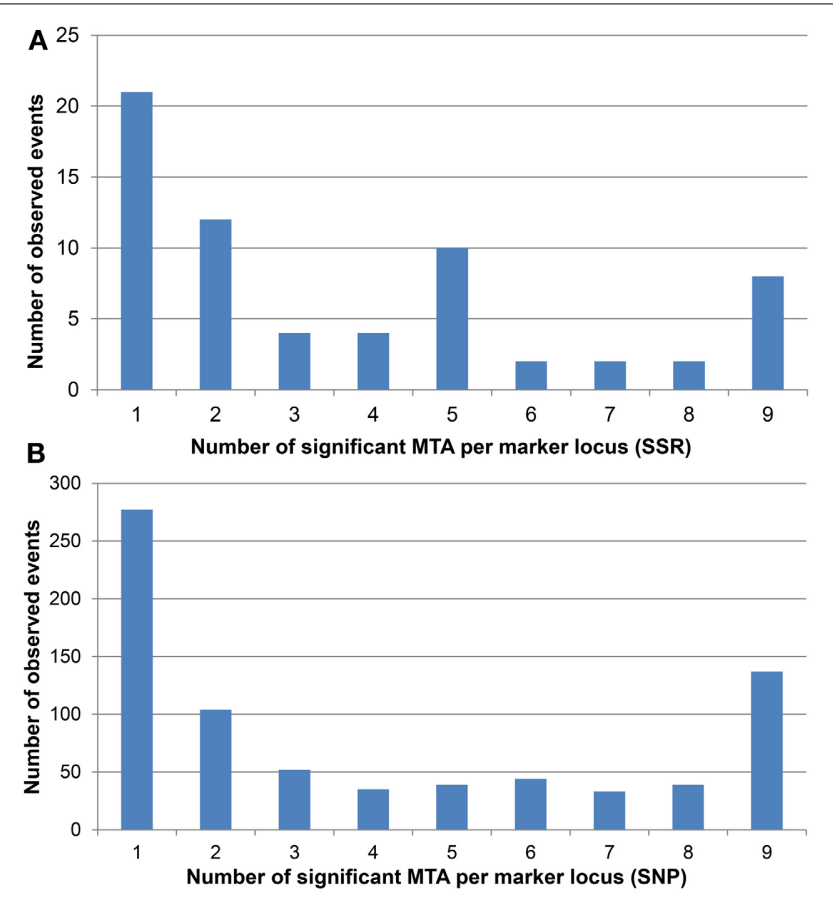

FIGURE 3 | Number of significant MTA for each (A) SSR and (B) SNP marker locus. The significant MTA per marker locus range from one to a maximum of nine according to the eight environments plus BLUEs.

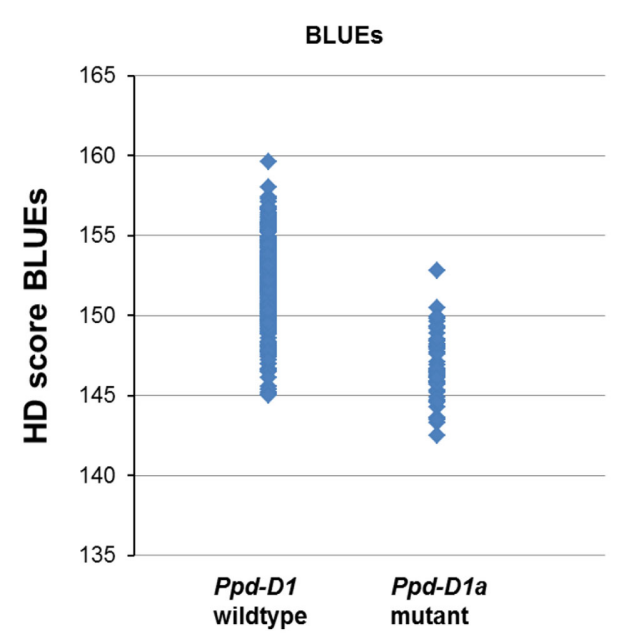

FIGURE 4 | Allelic effects for Ppd-D1 in a population of 372 European wheat varieties. Varieties carrying the mutant allele Ppd-D1a showed a decreased HD score BLUES resulting in an earlier heading.

BARC232_197 bp, and BARC232_232 bp, while no LD existed with Vrn-B1 (Supplemental file 14). Therefore the MTAs discovered by those SSR alleles are not based on LD to Vrn-B1 but most likely on LD to an $H d 6$ related gene in wheat. It can be concluded, that the gene from which Kukri_c10016_369 was derived, is an Hd6-related gene in wheat, which itself has a significant impact on $\mathrm{HD}$ or is in LD with another gene affecting HD.

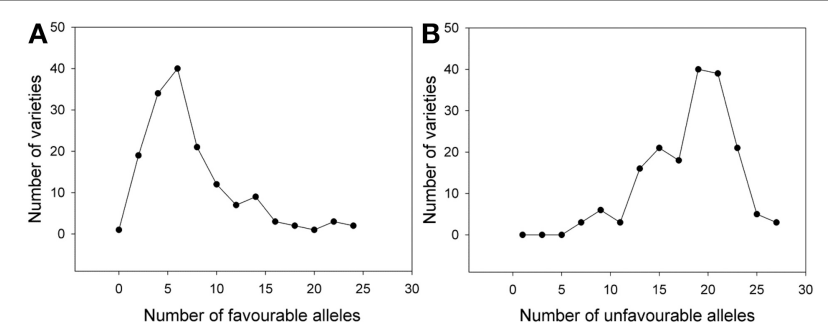

FIGURE 5 | Frequency of (A) favorable HD alleles and (B) unfavorable HD alleles from SSR markers in individual varieties. Most of the varieties carried between zero to ten favorable alleles decreasing the heading date and between ten to 25 unfavorable alleles increasing the heading date.

\section{DISCUSSION}

\section{COMPARISON OF MTAS DISCOVERED WITH SSR AND SNP MARKERS}

The chosen approach led to the discovery of a number of highly significant MTAs for HD in European winter wheat. In comparison to other traits, which were analyzed in the same set of varieties and molecular markers, the number of significant MTAs for HD was lower and less loci were involved. For resistance to Fusarium head blight a total of 794 significant MTAs $\left[-\log _{10}(P-\right.$ value) $\geq 3.0$ ], which included 323 SSR alleles, were detected in four environments (Kollers et al., 2013a), while for resistance to Septoria tritici blotch 115 MTAs were significant $\left[-\log _{10}(P\right.$ value $\geq 3.0$ ] involving 68 microsatellite loci in two environments (Kollers et al., 2013b). For HD, 340 MTAs detected by 79 SSR loci were significant $\left[-\log _{10}(P\right.$-value $\left.) \geq 3.0\right]$ in eight environments (Table 1). In a previous genome-wide association study involving a 227-wheat core collection and 760 molecular markers, consisting of mainly DArT markers, 62 markers individually associated to earliness components corresponding to 33 chromosomal regions, were identified (Le Gouis et al., 2012). This number corresponds well to the 30 loci identified in our study by SSRs, when considering the BLUEs only and when adjacent markers were combined to unified loci (Supplemental files 5, 6B, 7B). A meta-QTL analysis of the genetic control of ear emergence in elite European winter wheat germplasm discovered 19 meta-QTL regions (Griffiths et al., 2009).

Many marker loci were detected in two or more environments (Figure 3). This observation indicates the impact of major genes in shaping the genetically determined pattern of HD in winter wheat. It is also an indicator of a high reproducibility of the ranking of varieties considering the phenotypic data, which was confirmed by the high correlations observed between the environments (Supplemental file 2), though the environments covered a range of geographical latitudes ( 48.2 to $54.4^{\circ} \mathrm{N}$; Supplemental file 1) and various micro-climates in France and Germany.

Overall, the used number of SNP markers was higher with 7934 SNP markers compared to 770 SSR loci with a total of 3176 SSR alleles. After Bonferroni correction, 90 SSR markers remained significant as compared to 438 for the SNPs. These included 10 BLUEs for SSR and 51 BLUEs for SNPs (Supplemental files 5, 6B, 7B).

Though the overall number of SNP markers was higher than the SSR markers, there was less coverage for specific 


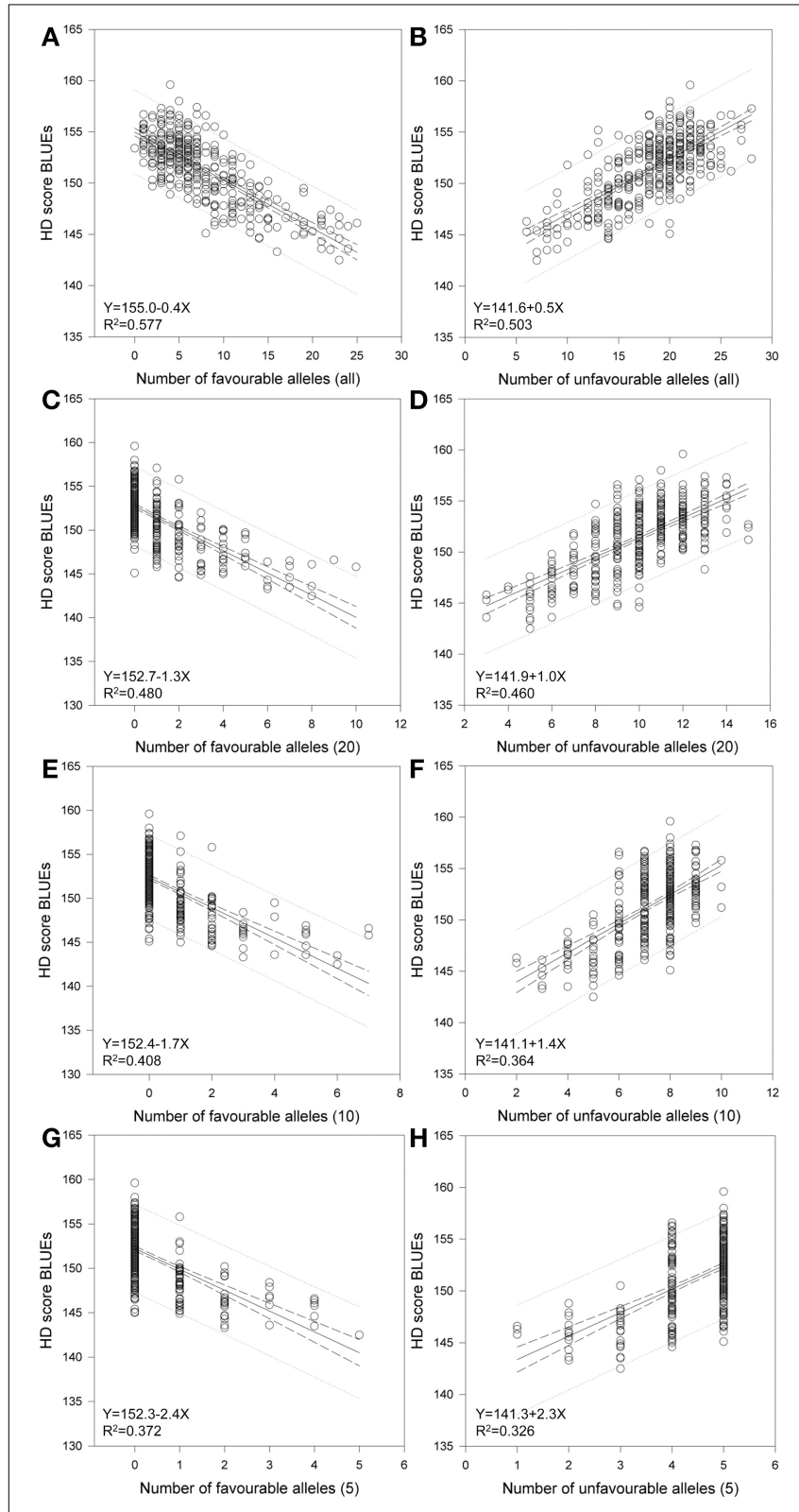

FIGURE 6 | Regression of favorable and unfavorable HD alleles. Linear regression resulted in a relationship of HD-BLUEs score and number of favorable and number of unfavorable alleles in 372 wheat varieties. The calculations were performed for (A) all favorable and (B) all unfavorable alleles and included the SSR marker with significant association with a $-\log _{10}(P$-value $) \geq 3.0$. Additional calculation were done by taking the (C) 20 best and (D) 20 worst alleles, the (E) 10 best and (F) 10 worst alleles as well as the (G) 5 best and $\mathbf{( H )} 5$ worst alleles, which included the candidate gene Ppd-D1

chromosomes like $4 \mathrm{D}$ and $6 \mathrm{D}$, and many co-segregating loci resulted in a reduced number of haplotypes. Like the SSRs, the SNP markers often detected significant MTAs for HD in various environments with 137 SNP markers detecting all eight environments plus BLUEs (Figure 3B). Often SNPs, which cosegregated in the genetic map, were all involved in MTA detection, resulting in clusters of significant markers (Supplemental file 8).
The prerequisite for a detailed comparison of the significant SSR and SNP loci is a highly integrated map for both marker systems, which currently is not available yet. By comparing the chromosomal locations of the SNP and SSR maps (Supplemental file 8), it becomes obvious that several novel chromosomal locations were detected by the SNPs compared to the SSRs. Examples are a cluster of significant SNP markers at the distal end of chromosome 1AL (RAC875_c21411_162, wsnp_BE444305A_Td_2_1, wsnp_RFL_Contig3542_3718200, RAC875_c12348_720) and a cluster of highly significant markers on the distal end of chromosome 3DS (Excalibur_c19658_127, Kukri_c24488_431, Kukri_rep_c94244_223).

\section{CANDIDATE GENES FOR MTAs WITH SSR}

The presence of detailed mapping information of the SSR markers in various maps (Somers et al., 2004; Ganal and Röder, 2007; http://wheat.pw.usda.gov/GG2/index.shtml) allowed the comparison of our association results to the mapping positions of known candidate genes. MTAs most likely corresponding to the series of photoperiodism genes $P p d$ on the short arms of the homeologous group 2 chromosomes were detected for chromosome 2A (markers WMC177 and WMC522) and chromosome 2B (marker GWM4167). Ppd-B1 was previously mapped in the interval of GWM257 and GWM148 (Mohler et al., 2004), which includes marker GWM4167 in our map. The marker for candidate gene $P p d-D 1$ was the most significant marker based on the observed additive effects, however no significant SSR markers in the expected region on chromosome 2DS in the vicinity of marker GWM261 (Pestsova and Röder, 2002) were observed. One possible reason may be the existence of a 21 centiMorgan gap in the genomic region between WMC112 and BARC168. If Ppd-D1 is located in this gap, the extent of LD may not reach the flanking markers. An LD plot showed no LD with $r^{2}>0.1$ between the alleles of markers GWM261,WMC112 or BARC168 and the PpdD1 candidate gene (Supplemental file 15). The agronomic effects described for $P p d-D 1$ depended very much on the trial sites. In the UK, the $2 \mathrm{D}$ chromosome carrying $P p d-D 1$ reduced yield about $5-10 \%$, while in Yugoslavia the same genotypes increased yield about 30\% (Worland et al., 1998). The advantages of earlier heading of $P p d-D 1$ insensitive varieties in Southern European countries were attributed to an escape of heat and drought during summer. The genotyping of the candidate marker for $P p d-D 1$ indeed showed that the insensitive mutant allele is mainly present in varieties originating from South France (Supplemental file 1). $P p d-B 1$ (old nomenclature $P p d 2$ ) was described as a weaker gene for photoperiod insensitivity than $P p d-D 1$ with a strong influence of the environmental conditions on the agronomic effects (Worland et al., 1998). For central European varieties, where the effects of $P p d-D 1$ are too strong, $P p d-B 1$ may provide a moderate gene for the adaptation to hot and dry summers. An epistatic interaction between $P p d-B 1$ and $P p d-D 1$ was described in a doubled haploid mapping population (Hanocq et al., 2004). We found in our list of the markers with the strongest additive effects besides the $P p d-D 1$ candidate gene also GWM4167 associated with $P p d-B 1$ and WMC522 associated with $P p d-A 1$ (Table 2), emphasizing the presence and importance of these genes in the Central European varieties. 
Table 2 | List of the best favorable and worst unfavorable alleles.

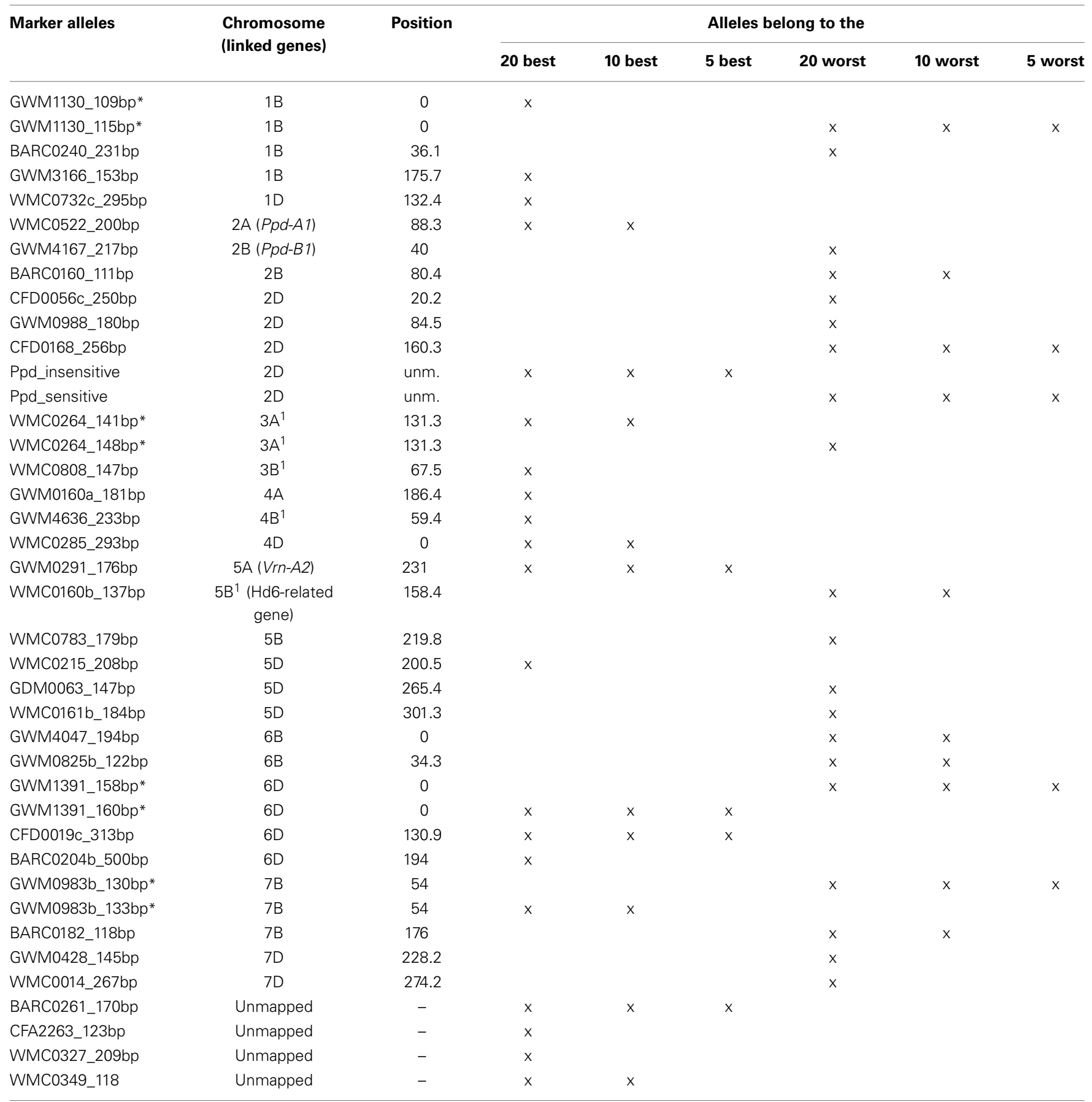

${ }^{*}$ Markers with positive and negative additive effects, ${ }^{1}$ coincides with meta-QTL described by Griffiths et al. (2009).

A series of vernalization genes determining the growth habit of wheat, has been described and functionally characterized (Trevaskis et al., 2007; Distelfeld et al., 2009). These include the series of $V R N-1$ genes on homeologous chromosomes $5 \mathrm{~A}, 5 \mathrm{~B}$, and 5D (Yan et al., 2003), the Vrn-A2 gene on the distal end of chromosome 5AL (Yan et al., 2004), the Vrn-B3 gene on chromosome arm 7BS (Yan et al., 2006) and the Vrn-D4 gene in the centromeric region of chromosome 5D (Yoshida et al., 2010). In winter wheat usually all four genes $V r n-A 1, V r n-B 1, V r n-D 1$, and $V r n-B 3$ are present in recessive state, while the presence of one or more dominant alleles was only detected in spring wheat varieties (Zhang et al., 2008). This assumption did not verify for Vrn$B 1$ in our set of varieties, which had a dominant allele for three spring varieties, but also three winter varieties (Buteo, Discus, and Lona). No significant associations were found for this rare $\mathrm{Vrn}$ $B 1$ allele, which indicated that the highly significant association 
of SSR markers WMC160 and BARC232 on chromosome 5BL was not caused by LD to $V r n-B 1$, but probably by the presence of another gene. Also on the respective chromosomal locations for $\mathrm{Vrn}-\mathrm{A} 1$ on chromosome 5A and $\mathrm{Vrn}$-B3 on chromosome 7BS no significant SSR markers were detected. The highly significant MTAs detected by marker GWM291 on the distal end of chromosome $5 \mathrm{~A}$ in all environments and BLUEs coincided with the location of $V r n-A 2$. Vrn-A2 has been described as floral repressor that delays flowering until plants are vernalized. Loss of function of Vrn-A2 results in spring types (Yan et al., 2004; Trevaskis et al., 2007). Allele GWM291_176 bp was among the five best markers based on the additive effects (Table 2). The vernalization gene $V r n-B 3$ is linked completely to a gene similar to Arabidopsis FLOWERING LOCUS T $(F T)$. Transcript levels of the barley and wheat orthologs, designated as $H v F t$ and TaFT, respectively, are significantly higher in plants for the dominant Vrn3 alleles (early flowering) than in plants homozygous for the recessive vrn3 alleles (late flowering) (Yan et al., 2006). It was shown that nucleotide polymorphisms on $\mathrm{A}$ and $\mathrm{D}$ copies of the wheat FT gene were associated with variations for HD in a collection of 239 diverse lines (Bonnin et al., 2008). Gene copy TaFT-7D was mapped in the region of marker GWM44 in the central region of chromosome 7D (Bonnin et al., 2008). We detected three significant markers (GWM4335, GWM3062, BARC126) located distal to GWM44, which may or may not be in LD with TaFT-7D.

Several of our MTAs coincided with published meta-QTL regions for HD (Hanocq et al., 2007; Griffiths et al., 2009). Besides the already described genomic regions on homeologous groups 2 and 5, the marker WMC264 on chromosome 3A detecting multiple MTAs coincided with a meta-QTL described by Griffiths et al. (2009). Two alleles of WMC264 with opposing effects are included in our table of best and worst alleles (Table 2). On chromosome 3B, QTL for HD were described for the genomic region proximal to GWM493 (Pánková et al., 2008; Griffiths et al., 2009), which may coincide with the MTAs detected by WMC808 in our study. The studies of Griffiths et al. (2009) as well as Hanocq et al. (2007) describe QTLs linked to GWM251 on chromosome 4B. Marker GWM4636, which detected multiple MTAs in our study, is the neighboring marker in our map. In the Charger $\times$ Badger population a QTL was described in the interval GWM408 to BARC140 on chromosome 5BL. This interval includes WMC160 and BARC232 which detected both highly significant MTAs in multiple environments in our study. We assume that this MTA is independent of $V r n-B 1$, since the candidate markers for Vrn-B1 were not significant. A second QTL was described by Griffiths et al. on chromosome 5B located in the interval GWM540 to GWM544. This interval includes WMC376 in our map, which detected multiple MTAs. Markers for both QTL regions on chromosome 5B (WMC160 and WMC783) are included in our selected list of markers (Table 2). Marker WMC14 on chromosome 7DL detected both QTL in the studies of Griffiths et al. (2009) and Hanocq et al. (2007) as well as MTAs in our study. A QTL extending distal to GWM44 on chromosome 7DS in the Savannah $\times$ Rialto population (Griffiths et al., 2009) coincided with the MTAs detected by markers GWM4335, GWM3062, and BARC126 in our study. On chromosome $1 \mathrm{BL}$, the QTL in the interval WMC44 to BARC80 detected in the Avalon $\times$ Cadenza population (Griffiths et al., 2009) coincided with MTAs detected by markers GWM3166 and GWM1364 in our study. The QTL detected in the region of GWM18 on chromosome 1BS (Griffiths et al., 2009) covered BARC240 showing a MTA in our study, however the highly significant GWM1130 further distal seems not to be included in the described meta-QTL region. In the association study of Le Gouis et al. (2012) marker GWM 642 detected an association for HD in non-vernalized plants. This marker is in close vicinity to WMC732 detecting multiple MTAs in our study. The detailed comparison to the other associations described by Le Gouis et al. (2012) is difficult due to the lack of common markers.

\section{ASSOCIATIONS DETECTED WITH SNPS AND EXPLOITATION OF SYNTENY}

The SNP markers on the array are mostly new and therefore no literature data on MTAs involving these markers are available. While the SSR markers are mainly based on genomic sequences, the SNPs were mostly derived from genes and can therefore be used to establish the synteny to rice and other grasses, where full genome sequences are available (International Rice Genome Sequencing Project, 2005; The International Brachypodium Initiative, 2010).

Our results indicated, that a wheat gene on chromosome 5B, which is related to the Hd6 gene family of rice, has a major impact on heading time in wheat. Several earliness per se QTL on chromosome $5 \mathrm{~B}$ were described in the Cutler $\times$ Barrie spring wheat population (Kamran et al., 2013). The earliness per se QTL QFlt.dms-5B.1 inducing earlier flowering could help to elongate the grain filling duration for higher grain yield (Kamran et al., 2013). The SSR marker GWM371 linked to QFlt.dms$5 B .1$ is located in some distance from the location of WMC160 and BARC232 according to Ganal and Röder (2007), indicating that QFlt.dms-5B.1 is different from the Hd6 related SNP marker association of marker Kukri_c10016_369.

The synteny to rice can also be used to indirectly compare the mapping of our significant wheat markers to published literature data. An example is a cluster of three highly significant wheat SNP markers on chromosome 1AL which was not discovered by SSR markers (Supplemental file 8). On chromosome $1 \mathrm{AL}$ the fine mapping of the earliness per se gene Eps- $A^{m} 1$ was reported (Valárik et al., 2006; Lewis et al., 2008). After establishing the synteny of rice of our significant loci (LOC_Os05g45930 for wsnp_BE444305A_Td_2_1 and for wsnp_RFL_Contig3542_ 3718200; LOC_Os05g45900 for RAC875_c21411_162) it was possible to compare to the location of $E p s-A^{m} 1$ established by Valárik et al. (2006) between markers Adk1 (LOC_Os05g51560) and Pp2c (LOC_Os05g51510). Based on the rice syntenic loci our locus appears to be different from gene Eps- $A^{m} 1$. A similar example exists for chromosome $3 \mathrm{~A}$ for which the presence of earliness per se locus Eps-3A $A^{m}$ was reported (Gawronski and Schnurbusch, 2012). The syntenic locus of the significant wheat marker wsnp_ex_c8884_14841846 (LOC_Os01g64490) in our map did not match the location of the markers PAV_295_296 (LOC_Os01g740300), CAPS_zt4_zt5 (LOC_Os01g741100) and CAPS_281_282 (LOC_Os01g741400) reported to be linked to Eps-3A ${ }^{m}$ (Gawronski and Schnurbusch, 2012). 
In barley, the circadian clock gene early maturity 8 (eam8) was identified as an ortholog of the Arabidopsis thaliana circadian clock regulator early flowering (elf3) (Faure et al., 2012; Zakhrabekova et al., 2012). The reported syntenic region in rice, ranging from LOC_Os5g51560 to LOC_Os05g51650 did not include any significant markers in our list, for which synteny to rice could be established. For the barley early maturity 10 (eam10) gene the Hvluxl gene, an ortholog to the Arabidopsis circadian gene LUX ARRHYTHMO, was proposed as a candidate (Campoli et al., 2013) with orthologs in rice (LOC_Os01g74020) and Brachypodium (Bradi2g62070). For none of these orthologous sites candidates were found in our wheat association panel.

\section{CONCLUSIONS}

Genome wide associations for HD in European winter wheat were established for SSR as well as SNP markers. It could be shown that a number of known regulatory photoperiodism genes, such as $P p d-A 1, P p d-B 1, P p d-D 1$ and the vernalization gene $V r n-A 2$ have a major impact in shaping the genetic architecture of HD. The distribution of MTAs in multiple environments led however to the conclusion, that many more major genetic loci are involved. We were able to demonstrate the significance of an $H d 6$ related gene marker on chromosome 5BL, which indicated the importance of the $H d 6$ related gene for HD in wheat.

The dependence of the number of favorable alleles of SSR markers in a variety in relation to the HD-BLUEs indicated the strong genetic component in HD. By considering only five markers, it was possible to obtain a regression with $R^{2}=0.372$. Therefore, the described list of markers (Table 2 ) could be used for the stacking of alleles by marker assisted breeding and for the development of well adapted varieties for specific environments and geographical locations.

\section{ACKNOWLEDGMENTS}

This research was funded by the Plant Biotechnology program of the German Federal Ministry of Education and Research (BMBF) within the frame of the projects GABI-Wheat and VALID (project numbers 0315067 and 0315947). We thank K. Neumann and J. Reif for help in statistical analysis.

\section{SUPPLEMENTARY MATERIAL}

The Supplementary Material for this article can be found online at: http://www.frontiersin.org/journal/10.3389/fpls.2014.00217/ abstract

\section{REFERENCES}

Andrés, F., and Coupland, G. (2012). The genetic basis of flowering responses to seasonal cues. Nat. Rev. Genet. 13, 627-639. doi: 10.1038/nrg3291

Beales, J., Turner, A., Griffiths, S., Snape, J., and Laurie, D. A. (2007). A PseudoResponse Regulator is misexpressed in the photoperiod insensitive Ppd-D1a mutant of wheat (Triticum aestivum L.). Theor. Appl. Genet. 115, 721-733. doi: 10.1007/s00122-007-0603-4

Bogard, M., Jourdan, M., Allard, V., Martre, P., Perretant, M. R., Ravel, C., et al. (2011). Anthesis date mainly explained correlations between post-anthesis leaf senescence, grain yield, and grain protein concentration in a winter wheat population segregating for flowering time QTLs. J. Exp. Bot. 62, 3621-3636. doi: $10.1093 / \mathrm{jxb} / \mathrm{err} 061$

Bonnin, I., Rousset, M., Madur, D., Sourdille, P., Dupuits, C., Brunel, D., et al. (2008). FT genome A and D polymorphisms are associated with the variation of earliness components in hexaploid wheat. Theor. Appl. Genet. 116, 383-394. doi: 10.1007/s00122-007-0676-0
Campoli, C., Pankin, A., Drosse, B., Casao, C., Davis, S. J., and von Korff, M. (2013). HvLUX1 is a candidate gene underlying the early maturity 10 locus in barley: phylogeny, diversity, and interactions with the circadian clock and photoperiodic pathways. New Phytol. 199, 1045-1059. doi: 10.1111/nph.12346

Cavanagh, C. R., Chao, S., Wang, S., Huang, B. E., Stephen, S., Kiani, S., et al. (2013). Genome-wide comparative diversity uncovers multiple targets of selection for improvement in hexaploid wheat landraces and cultivars. Proc. Natl. Acad. Sci. U.S.A. 110, 8057-8062. doi: 10.1073/pnas.1217133110

Cockram, J., Jones, H., Leigh, F. J., O’Sullivan, D., Powell, W., Laurie, D. A., et al. (2007). Control of flowering time in temperate cereals: genes, domestication, and sustainable productivity. J. Exp. Bot. 58, 1231-1244. doi: 10.1093/jxb/erm042

Crossa, J., Burgueno, J., Dreisigacker, S., Vargas, M., Herrera-Foessel, S. A., Lillemo, M., et al. (2007). Association analysis of historical bread wheat germplasm using additive covariance of relatives and population structure. Genetics 177, 1889-1913. doi: 10.1534/genetics.107.078659

Distelfeld, A., Li, C., and Dubcovsky, J. (2009). Regulation of flowering time in temperate cereals. Curr. Opin. Plant Biol. 12, 1-7. doi: 10.1016/j.pbi.2008.12.010

Faricelli, M. E., Valárik, M., and Dubcovsky, J. (2010). Control of flowering time and spike development in cereals: the earliness per se Eps-1 region in wheat, rice, and Brachypodium. Funct. Integr. Genomics 10, 293-306. doi: 10.1007/s10142009-0146-7

Faure, S., Turner, A. S., Gruszka, D., Christodoulou, V., Davis, S. J., von Korff, M., et al. (2012). Mutation at the circadian clock gene EARLY MATURITY 8 adapts domesticated barley (Hordeum vulgare) to short growing seasons. Proc. Natl. Acad. Sci. U.S.A. 109, 8328-8333. doi: 10.1073/pnas.1120496109

Ganal, M. W., and Röder, M. S. (2007). "Microsatellite and SNP markers in wheat breeding," in Genomics Assisted Crop Improvement: Vol. 2: Genomics Applications in Crops, eds R. K. Varshney and R. Tuberosa (Dordrecht: Springer), 1-24.

Gawronski, P., and Schnurbusch, T. (2012). High-density mapping of the earliness per se-3A $\mathrm{A}^{m}\left(E p s-3 A^{m}\right)$ locus in diploid einkorn wheat and its relation to the syntenic regions in rice and Brachypodium distachyon L. Mol. Breed. 30, 1097-1108. doi: 10.1007/s11032-011-9697-0

Griffiths, S., Simmonds, J., Leverington, M., Wang, Y., Fish, L., Sayers, L., et al. (2009). Meta-QTL analysis of the genetic control of ear emergence in elite European winter wheat germplasm. Theor. Appl. Genet. 119, 383-395. doi: 10.1007/s00122-009-1046-x

Hamblin, M. T., Buckler, E. S., and Jannink, J.-L. (2011). Population genetics of genomics-based crop improvement methods. Trends Genet. 27, 98-106. doi: 10.1016/j.tig.2010.12.003

Hanocq, E., Laperche, A., Jaminon, O., Lainé, A.-L., and Le Gouis, J. (2007). Most significant genome regions involved in the control of earliness traits in bread wheat, as revealed by QTL meta-analysis. Theor. Appl. Genet. 114, 569-584. doi: 10.1007/s00122-006-0459-z

Hanocq, E., Niarquin, M., Heumez, E., Rousset, M., and Le Gouis, J. (2004). Detection and mapping of QTL for earliness components in a bread wheat recombinant inbred lines population. Theor. Appl. Genet. 110, 106-115. doi: 10.1007/s00122-004-1799-1

Hardy, O. J., and Vekemans, X. (2002). SPAGEDi: a versatile computer program to analyse spatial genetic structure at the individual or population levels. Mol. Ecol. Notes 2, 618-620. doi: 10.1046/j.1471-8286.2002.00305.x

Higgins, J. A., Bailey, P. C., and Laurie, D. A. (2010). Comparative genomics of flowering time pathways using Brachypodium distachyon as a model for the temperate grasses. PLOS ONE 5:e10065. doi: 10.1371/journal.pone.00 10065

International Rice Genome Sequencing Project. (2005). The map-based sequence of the rice genome. Nature 436, 793-800. doi: 10.1038/nature03895

Jung, C., and Müller, A. E. (2009). Flowering time control and application in plant breeding. Trends Plant Sci. 14, 563-573. doi: 10.1016/j.tplants.2009.07.005

Kamran, A., Iqubal, M., Navabi, A., Randhawa, H., Pozniak, C., and Spaner, D. (2013). Earliness per se QTLs and their interaction with the photoperiod insensitive allele Ppd-D1a in the Cutler $\times$ AC Barrie spring wheat population. Theor. Appl. Genet. 126, 1965-1976. doi: 10.1007/s00122-013-2110-0

Khlestkina, E. K., Giura, A., Röder, M. S., and Börner, A. (2009). A new gene controlling the flowering response to photoperiod in wheat. Euphytica 165, 579-585. doi: 10.1007/s10681-008-9783-5

Kollers, S., Rodemann, B., Ling, J., Korzun, V., Ebmeyer, E., Argillier, O., et al. (2013a). Whole genome association mapping of Fusarium head blight resistance in European winter wheat (Triticum aestivum L.). PLoS ONE 8:e57500. doi: 10.1371/journal.pone.0057500 
Kollers, S., Rodemann, B., Ling, J., Korzun, V., Ebmeyer, E., Argillier, O., et al. (2013b). Genetic architecture of resistance to Septoria tritici blotch (Mycosphaerella graminicola) in European winter wheat. Mol. Breed. 32, 411-423. doi: 10.1007/s11032-013-9880-6

Laurie, D. A., Pratchett, N., Bezant, J. H., and Snape, J. W. (1995). RFLP mapping of five major genes and eight quantitative trait loci controlling flowering time in a winter $\times$ spring barley (Hordeum vulgare L.) cross. Genome 38, 575-585. doi: $10.1139 / \mathrm{g} 95-074$

Le Gouis, J., Bordes, J., Ravel, C., Heumez, E., Faure, S., Praud, S., et al. (2012). Genome-wide association analysis to identify chromosomal regions determining components of earliness in wheat. Theor. Appl. Genet. 124, 597-611. doi: 10.1007/s00122-011-1732-3

Letta, T., Maccaferri, M., Badebo, A., Ammer, K., Ricci, A., Crossa, J., et al. (2013). Searching for novel sources of field resistance to Ug99 and Ethiopian stem rust races in durum wheat via association mapping. Theor. Appl. Genet. 126, 1237-1256. doi: 10.1007/s00122-013-2050-8

Lewis, S., Faricelli, M. E., Appendino. M. L., Valárik, M., and Dubcovsky. J. (2008). The chromosome region including earliness per se locus Eps- $A^{m} 1$ affects the duration of early developmental phases and spikelet number in diploid wheat. J. Exp. Bot. 59, 3595-3607. doi: 10.1093/jxb/ern209

Maccaferri, M., Sanguineti, M. C., Mantovani, P., Demontis, A., Massi, A., Ammar, K., et al. (2010). Association mapping of leaf rust response in durum wheat. Mol. Breed. 26, 189-228. doi: 10.1007/s11032-009-9353-0

Matthies, I. E., van Hintum, T., Weise, S., and Röder, M. S. (2012). Population structure revealed by different marker types (SSR or DArT) has an impact on the results of genome-wide association mapping in European barley cultivars. Mol. Breed. 30, 951-966. doi: 10.1007/s11032-011-9678-3

Miedaner, T., Würschum, T., Maurer, H. P., Korzun, V., Ebmeyer, E., and Reif, J. C. (2011). Association mapping for Fusarium head blight resistance in European soft winter wheat. Mol. Breed. 28, 647-655. doi: 10.1007/s11032-0109516-z

Mohler, V., Lukman, R., Ortiz-Islas, S., William, M., Worland, A. J., Van Beem, J., et al. (2004). Genetic and physical mapping of photoperiod insensitive gene $P p d-B 1$ in common wheat. Euphytica 138, 33-40. doi: 10.1023/B:EUPH.0000047056.58938.76

Neumann, K., Kobiljski, B., Dencic, S., Varshney, R. K., and Börner, A. (2011). Genome-wide association mapping: a case study in bread wheat (Triticum aestivum L.). Mol. Breed. 27, 37-58. doi: 10.1007/s11032-010-9411-7

Pánková, K., Milec, Z., Simmonds, J., Leverington-Waite, M., Fish, L., and Snape, J. W. (2008). Genetic mapping of a new flowering time gene on chromosome 3B of wheat. Euphytica 164, 779-787. doi: 10.1007/s10681-008-9727-0

Pestsova, E., and Röder, M. S. (2002). Microsatellite analysis of wheat chromosome $2 \mathrm{D}$ allows the reconstruction of chromosomal inheritance in pedigrees of breeding programmes. Theor. Appl. Genet. 106, 84-91. doi: 10.1007/s00122002-0998-x

Pin, A. P., Zhang, W., Vogt, S. H., Dally, N., Büttner, B., Schulze-Buxloh, G., et al. (2012). The role of a pseudo-response regulator gene in life cycle adaption and domestication of beet. Curr. Biol. 22, 1095-1101. doi: 10.1016/j.cub.2012.04.007

Poland, J. A., Brown, P. J., Sorrells, M. E., and Jannink, J.-L. (2012). Development of high-density genetic maps for barley and wheat using a novel twoenzyme genotyping-by-sequencing approach (2012). PLoS ONE 7:e32253. doi: 10.1371/journal.pone.0032253

Reif, J. C., Maurer, H. P., Korzun, V., Ebmeyer, E., Miedaner, T., and Würschum, T. (2011). Mapping QTLs with main and epistatic effects underlying grain yield and heading time in soft winter wheat. Theor. Appl. Genet. 123, 283-292. doi: 10.1007/s00122-011-1583-y

Röder, M. S., Korzun, V., Wendehake, K., Plaschke, J., Tixier, M.-H., Leroy, P., et al. (1998). A microsatellite map of wheat. Genetics 149, 2007-2023.

Rousset, M., Bonnin, I., Remoué, C., Falque, M., Rhoné, B., Veyrieras, J.-B., et al. (2011). Deciphering the genetics of flowering time by an association study on candidate genes in bread wheat (Triticum aestivum L.). Theor. Appl. Genet. 123, 907-926. doi: 10.1007/s00122-011-1636-2

Salse, J., Abrouk, M., Bolot, S., Guilhot, N., Courcelle, E., Faraut, T., et al. (2009). Reconstruction of monocotelydonous proto-chromosomes reveals faster evolution in plants than in animals. Proc. Natl. Acad. Sci. U.S.A. 106, 14908-14913. doi: 10.1073/pnas.0902350106

Somers, D. J., Issac, P., and Edwards, K. (2004). A high-density microsatellite consensus map for bread wheat (Triticum aestivum L.). Theor. Appl. Genet. 109, 1105-1114. doi: 10.1007/s00122-004-1740-7
Sorrells, M. E., Gustafson, J. P., Somers, D., Chao, S., Benscher, D., Guedira-Brown, G., et al. (2011). Reconstruction of the synthetic W7984 × Opata M85 wheat reference population. Genome 54, 875-882. doi: 10.1139/g11-054

Sourdille, P., Snape, J. W., Cadalen, T., Charmet, G., Nakata, N., Bernard, S., et al. (2000). Detection of QTLs for heading date and photoperiod response in wheat using a doubled-haploid population. Genome 43, 487-494. doi: 10.1139/ g00-013

Takahashi, Y., Shomura, A., Sasaki, T., and Yano, M. (2001). Hd6, a rice quantitative trait locus involved in photoperiod sensitivity, encodes the $\alpha$ subunit of protein kinase CK2. Proc. Natl. Acad. Sci. U.S.A. 98, 7922-7927. doi: $10.1073 /$ pnas. 111136798

The International Brachypodium Initiative. (2010). Genome sequencing and analysis of the model grass Brachypodium distachyon. Nature 463, 763-768. doi: 10.1038 /nature08747

Trevaskis, B., Hemming, M. N., Dennis, E. S., and Peacock, W. J. (2007). The molecular basis of vernalization-induced flowering in cereals. Trend Plant Sci. 12, 352-357. doi: 10.1016/j.tplants.2007.06.010

Turner, A., Beales, J., Faure, S., Dunford, R. P., and Laurie, D. A. (2005). The pseudo-response regulator Ppd-H1 provides adaption to photoperiod in barley. Science 310, 1031-1034. doi: 10.1126/science.1117619

Valárik, M., Linkiewicz, A. M., and Dubcovsky, J. (2006). A microlinearity study at the earliness per se gene Eps- $A^{m} 1$ region reveals an ancient duplication that preceeded the wheat-rice divergence. Theor. Appl. Genet. 112, 945-957. doi: 10.1007/s00122-005-0198-6

Wang, G., Schmalenbach, I., von Korff, M., Léon, J., Kilian, B., Rode, J., et al. (2010). Association of barley photoperiod and vernalization genes with flowering time and agronomic traits in a $\mathrm{BC} 2 \mathrm{DH}$ population and a set of wild barley introgression lines. Theor. Appl. Genet. 120, 1559-1574. doi: 10.1007/s00122-0101276-y

Wang, L., Ge, H., Hao, C., Dong, Y., and Zhang, X. (2012). Identifiying loci influencing 1000-kernel weight in wheat by microsatellite screening for evidence of selection during breeding. PLoS ONE 7:e29432. doi: 10.1371/journal.pone.0029432

Wang, S., Wong, D., Forrest, K., Allen, A., Chao, S., Huang, B., et al. (2014). Characterization of polyploid wheat genomic diversity using a high-density 90,000 SNP array. Plant Biotechnol. J. doi: 10.1111/pbi.12183. [Epub ahead of print].

Worland, A. J. (1996). The influence of flowering time genes on environmental adaptability in European wheats. Euphytica 89, 49-57. doi: 10.1007/BF00015718

Worland, A. J., Börner, A., Korzun, V., Li, W. M., Petrovic, S., and Sayers, E. J. (1998). The influence of photoperiod genes on the adaptability of European winter wheats. Euphytica 100, 385-394. doi: 10.1023/A:1018327700985

Yan, L., Fu, D., Li, C., Blechl, A., Tranquilli, G., Bonafede, M., et al. (2006). The wheat and barley vernalization gene VRN3 is an orthologue of FT. Proc. Natl. Acad. Sci. U.S.A. 103, 19581-19586. doi: 10.1073/pnas.0607142103

Yan, L., Loukoianov, A., Blechl, A., Tranquilli, G., Ramakrishna, W., SanMiguel, P., et al. (2004). The wheat VRN2 gene is a flowering repressor down-regulated by vernalization. Science 303, 1640-1644. doi: 10.1126/science.1094305

Yan, L., Loukoianov, A., Tranquilli, G., Helguera, M., Fahima, T., and Dubcovsky, J. (2003). Positional cloning of the wheat vernalization gene VRN1. Proc. Natl. Acad. Sci. U.S.A. 100, 6263-6268. doi: 10.1073/pnas.0937399100

Yoshida, T., Nishida, H., Zhu, J., Nitcher, R., Distelfeld, A., Akashi, Y., et al. (2010). Vrn-D4 is a vernalization gene located on the centromeric region of chromosome 5D in hexaploid wheat. Theor. Appl. Genet. 120, 543-552. doi: 10.1007/s00122-009-1174-3

Yu, L.-X., Lorenz, A., Rutkoski, J., Singh, R. P., Bhavani, S., Huerto-Espino, J., et al. (2011). Association mapping and gene-gene interaction for stem rust resistance in CIMMYT spring wheat germplasm. Theor. Appl. Genet. 123, 1257-1268. doi: 10.1007/s00122-011-1664-y

Yu, L.-X., Morgounov, A., Wanyera, R., Keser, M., Singh, S. K., and Sorrells, M. (2013). Identification of Ug99 stem rust resistance loci in winter wheat germplasm using genome-wide association analysis. Theor. Appl. Genet. 125, 749-758. doi: 10.1007/s00122-012-1867-x

Zakhrabekova, S., Gough, S. P., Braumann, I., Müller, A. H., Lundqvist, J., Ahmann, K., et al. (2012). Induced mutations in circadian clock regulator Mat-a facilitated short-season adaptation and rage extension in cultivated barley. Proc. Natl. Acad. Sci. U.S.A. 109, 4326-4331. doi: 10.1073/pnas.1113009109

Zhang, X. K., Xiao, Y. G., Zhang, Y., Xia, X. C., Dubcovsky, J., and He, Z. H. (2008). Allelic variation at the vernalization genes $V r n-A 1, V r n-B 1, V r n-D 1$, and $V r n-B 3$ 
in Chinese wheat cultivars and their association with growth habit. Crop Sci. 48, 458-470. doi: 10.2135/cropsci2007.06.0355

Zhu, C., Gore, M., Buckler, E. S., and Yu, J. (2008). Status and prospects of association mapping in plants. Plant Genome 1, 5-20. doi: 10.3835/plantgenome2008. 02.0089

Conflict of Interest Statement: Sonja Kollers, Viktor Korzun, and Erhard Ebmeyer are employed by the company KWS LOCHOW GMBH, Odile Argillier, Gunther Stiewe, and Maike Hinze are employed by Syngenta Seeds $\mathrm{GmbH}$ and Martin W. Ganal, Jörg Plieske are employed by the company TraitGenetics GmbH. The companies have commercial interest in the results for application in variety development and for the provision of genotyping services. This does not alter the authors' adherence to all Frontiers policies on sharing data and materials. The authors declare that the research was conducted in the absence of any commercial or financial relationships that could be construed as a potential conflict of interest.
Received: 23 January 2014; accepted: 01 May 2014; published online: 20 May 2014. Citation: Zanke C, Ling J, Plieske J, Kollers S, Ebmeyer E, Korzun V, Argillier O, Stiewe G, Hinze M, Beier S, Ganal MW and Röder MS (2014) Genetic architecture of main effect QTL for heading date in European winter wheat. Front. Plant Sci. 5:217. doi: $10.3389 / \mathrm{fpls} .2014 .00217$

This article was submitted to Plant Genetics and Genomics, a section of the journal Frontiers in Plant Science.

Copyright (C) 2014 Zanke, Ling, Plieske, Kollers, Ebmeyer, Korzun, Argillier, Stiewe, Hinze, Beier, Ganal and Röder. This is an open-access article distributed under the terms of the Creative Commons Attribution License (CC BY). The use, distribution or reproduction in other forums is permitted, provided the original author(s) or licensor are credited and that the original publication in this journal is cited, in accordance with accepted academic practice. No use, distribution or reproduction is permitted which does not comply with these terms. 